\title{
EL DORADO(1988), DE CARLOS SAURA: FUSIÓN DE MITO UTÓPICO Y DE REALIDAD
}

\author{
Raquel ROCAMORA MONTENEGRO
}

Universidad de Alicante

\section{RESUMEN}

El descubrimiento del novus orbis trajo consigo el choque de dos culturas, una de ellas subalterna -la indígena o americana- y otra dominante -la española y, por extensión, la europea-. Esta última proyectó en el nuevo continente, caracterizado por una naturaleza indómita, seres incivilizados según la versión eurocentrista y fuentes de recursos fecundas, sus ansias de poder y de riqueza. La imagen de América como tierra de la abundancia ocasionó que muchos conquistadores y expedicionarios se lanzaran a la búsqueda de lugares míticos para prosperar social y económicamente, entre los que figuraba la ciudad de El Dorado. Sus aventuras han sido recreadas en algunas ocasiones en el cine a partir de diferentes propuestas, como la de Carlos Saura, que se centra en la fallida empresa de Pedro de Ursúa y Lope de Aguirre, pues no encontraron el ansiado lugar.

Palabras clave: expedición, conquistadores, El Dorado, Pedro de Ursúa, mito, oro, Lope de Aguirre.

\section{ABSTRACT}

The discovery of the novus orbis brought with it the clash of two cultures, one of them subaltern -the indigenous or American- and another dominant -the Spanish and, by extension, the European-. The latter projected on the new continent, characterized by an untamed nature, human beings uncivilized according to the eurocentric version and fertile resources, their cravings for power and wealth. The image of America as a land of abundance caused many conquerors and expeditionaries to launch themselves in search of mythical places to prosper socially and economically, among the city of El Dorado. Their adventures have been recreated in some cases in the cinema from different proposals, such as the one of Carlos Saura, which focuses on the failed business of Pedro de Ursúa and Lope de Aguirre, because they did not find the desired place.

Keywords: expedition, conquerors, El Dorado, Pedro de Ursúa, myth, gold, Lope de Aguirre. 


\section{INTRODUCCIÓN}

El descubrimiento de América, fechado en 1492, supuso, entre otros, el hallazgo de nuevas realidades referentes a la naturaleza, a los individuos y a las fuentes de recursos que sorprendieron al mundo. A partir de dicho momento, los conquistadores y expedicionarios de la época proyectaron sus deseos y sus anhelos más profundos en un continente desconocido que aumentaba su fantasía y su imaginación como lugar utópico en el que todo sueño se podría realizar. En ocasiones, a partir de un hecho o suceso real, surgieron distintos mitos relacionados, en su mayoría, con la riqueza material o espiritual de estas tierras, como lo demuestran la Ciudad de los Césares y la de El Dorado, el País de la Canela, la Fuente de la Eterna Juventud, el Rey Blanco y la Reina California y sus Amazonas, entre otros forjados en las Indias Occidentales.

La importancia concedida al oro por parte de los conquistadores y la abundancia de este preciado metal en América aparecen ya evidenciadas en el Diario de a bordo (14921504), de Cristóbal Colón ${ }^{1}$, en las Cartas de relación (1519-1526), de Hernán Cortés ${ }^{2}$ y en el Sumario de la Natural Historia de las Indias (1526), de Fernández de Oviedo3, entre otros. A pesar de los variados testimonios, en todos estos textos se presenta el oro como una fuente de riqueza material para los conquistadores, cuyo valor era diferente para los indios, pues, según explica Mora, «si bien los conquistadores perseguían afanosamente el oro solo con el fin de enriquecerse, para los indígenas precolombinos el brillante metal precioso tenía solo un valor simbólico y hasta sobrenatural, no monetario» (2014: 42).

La codicia del ser humano y su ambición de riquezas impulsaron a muchos hombres a adentrarse en peligrosas aventuras en tierras indómitas, de las cuales pocos de ellos salieron con vida. Gracias a estos testimonios tenemos hoy en día noticias de estas expediciones protagonizadas, en su mayoría, por españoles fascinados por el atractivo de una realidad que en nada se parecía a la que conocían hasta el momento. Una de las leyendas que se sembraron en dichas tierras es la de El Dorado, vinculada con una ciudad mítica caracterizada por la copiosidad de este metal tan codiciado por los expedicionarios.

El presente estudio recoge una aproximación al mito ya mencionado, a partir de la recreación cinematográfica llevada a cabo por el director español Carlos Saura en 1988.

1 «Entre los muchos indios que ayer habían venido a la nao, que les habían dado señales de haber en aquella isla oro y nombrado los lugares donde lo cogían, vido uno parece que más dispuesto y aficionado o que con más alegría le hablaba, y halagolo rogándole que se fuese con él a mostrarle las minas del oro. Esto trujo otro compañero o pariente consigo entre los otros lugares que nombraban donde se cogía el oro, dijeron de Cipango, el cual ellos llaman Cibao, y allí afirman que hay gran cantidad de oro, y que el cacique trae las banderas de oro de martillo» (Colón, 2006: 192).

2 «Viendo pues el dicho capitan como le habian muerto mas de la cuarta parte de su gente, y que todos los que le quedaban estaban heridos, y que él mismo tenia treinta y tantas heridas, y que estaba cuási muerto que no pensaria escaparse, volvió con los dichos navios y gente á la isla Fernandina, donde hicieron saber al dicho Diego Velazquez como habian hallado una tierra muy rica de oro, porque á todos los naturales de ella lo habian visto traer puesto, ya de ellos en las narices, ya de ellos en las orejas y en otras partes, y que en la dicha tierra habia edificios de cal y canto y mucha cantidad de otras cosas que de la dicha tierra publicaron de mucha admiracion y riquezas, y dijéronle que si él podia enviase navios á rescatar oro, que habria mucha cantidad de él» (Cortés, 1866: 3).

3 «Y pues aquí se trata del oro, paréceme que antes de pasar adelante y que se hable en otra cosa, se diga cómo los indios saben muy bien dorar las piezas de cobre o de oro muy bajo; lo cual ellos hacen, y les dan tan excelente color y tan subida, que parece que toda la pieza que así doran es de tan buen oro como si tuviese veinte y dos quilates o más» (Fernández, 2019: 107). 
En concreto, se presenta un análisis comparativo entre la historia que conocemos gracias a los cronistas y su plasmación por el cineasta aragonés, a la vez que se examinan ciertos aspectos relacionados con el filme -la interpretación de los actores y las características del rodaje relativas al vestuario, la ambientación, los decorados y la banda sonora-. Finalmente, se hace referencia a la valoración por parte de la crítica y se recogen unas conclusiones que resumen lo expuesto a lo largo del estudio.

\section{ORIGEN DE LA LEYENDA Y SU REFLEJO EN LA PELÍCULA ${ }^{4}$}

El mito llega a oídos de los españoles en 1534, cuando un indio chibcha, capturado en Latacunga por el capitán Luis Daza, cuenta la historia de una tierra llena de riquezas y de oro, probablemente para protegerse de la crueldad de los conquistadores con la intención de dirigirlos hacia lugares remotos. Esta referencia la relacionamos con la ciudad de El Dorado, donde se llevaba a cabo una ceremonia de ofrendas y presentes de oro, para cuya realización se destinaba una gran cantidad de este metal. Algunos investigadores han señalado como explicación la ceremonia de sucesión de los diferentes caciques de la tribu, mientras que otras versiones hablan sobre un rito de purificación o expiación, surgido a raíz de un fallecimiento, pues un jefe chibcha se enteró del adulterio cometido por su mujer y la sometió a crueles castigos. Como consecuencia, decidió suicidarse junto a su hija en la laguna, y su marido, para redimirse, inició la tradición de llevar a cabo una ceremonia con ofrendas de oro en el lugar en que su familia había perdido la vida. Dicha laguna se encontraría ubicada en el antiguo Virreinato de Nueva Granada -la zona central de la actual Colombia-, aunque a lo largo de la historia se han sucedido diferentes localizaciones atendiendo a las distintas versiones de la historia.

Según la leyenda a la que nos acogemos, cada nuevo jefe del pueblo muisca de lengua chicha se cubría con polvo de oro, que se adhería al cuerpo con trementina, y se adentraba en una laguna sagrada junto a cuatro sacerdotes adornados con ornamentos de oro. En ella, realizaban ofrendas lanzando objetos fabricados con este preciado metal a su fondo. El resto del pueblo, por su parte, permanecía expectante en la orilla celebrando la coronación del nuevo líder al son de instrumentos, cuyo sonido se fundía con el producido por el ardor de grandes fogatas. El estruendo solamente desaparecía en el instante en que los sacerdotes solicitaban su cese cuando llegaba el momento de jurar fidelidad al nuevo jefe, pues cada miembro de la tribu debía gritar su aprobación desde la orilla.

La noticia de la riqueza de este pueblo dio lugar a diferentes expediciones a lo largo de la historia, aunque, como hemos señalado, su localización fue variando a medida que avanzaba el proceso de conquista y colonización del territorio sudamericano, y hubo quienes lo situaron en Venezuela, en Ecuador, en Bolivia, en Brasil y en Perú. Además de esta variación geográfica, también se sucedió una variación en la propia historia, pues evolucionó desde la alusión a un rey recubierto totalmente de oro hasta hacer referencia a una ciudad cuyos edificios eran también de este metal, que no llegó a encontrarse.

La crítica ha examinado la historicidad de este ritual, pues, según afirma Lucena, «la leyenda que dio origen al mito de El Dorado tiene un fondo de veracidad. En el territorio de los indios mwiska se hacían ofrendas a los espíritus o dioses de las lagunas, muchas de

4 Los datos de este partido están extraídos de: Barrientos, 1994: 309-314; Cervera, 2015: s. p.; Gómez, 1988: V-XXIII; Lucena, 1985: 4-32; Margalef, 2012: 1-30 y Mora, 2014: 40-47. 
ellas de oro [...], algunas de ellas atraerían más la atención de los penitentes, como parece ser el caso de Guatavita» (1985: 12). Así, el mito surge a raíz de la ceremonia celebrada para investir a los nuevos jefes en la laguna de Guatavita, localizada en la cordillera oriental de Colombia, en el municipio de Sesquilé, próximo a Bogotá. Este lugar, según defiende Osorio, "se trata de un centro religioso muy importante dentro del mundo chibcha y, en consecuencia, de un blanco tanto de la codicia de los conquistadores como del celo evangelizador» (2007: 50).

Fue Sebastián de Belalcázar el que tuvo conocimiento por primera vez de esta leyenda gracias al indio muisca ya mencionado, y se lanzó a la búsqueda de la mítica ciudad de oro sin informar a su superior, Francisco Pizarro. Posteriormente, este último mandó a uno de sus hombres, Gonzalo Jiménez de Quesada, para que imitase al anterior en su aventura, a la vez que se sumó a las expediciones iniciadas el gobernador alemán Ambrosio Alfinger.

Desde dicho momento, el mito se fue extendiendo entre las tropas españolas ${ }^{5}$, de modo que, tras estos pioneros, fueron muchos los conquistadores que desearon encontrar este lugar tan codiciado y se embarcaron, con este objetivo, a través del peligroso río Amazonas, entre quienes encontramos a Pedro de Ursúa. En septiembre de 1560, organizó una empresa para dar con El Dorado, bajo el mandato del virrey del Perú don Andrés Hurtado de Mendoza. Dicha expedición partió de Santa Cruz de Capocovar (Perú), a través del río Marañón, y concluyó en octubre de 1561 tras haber protagonizado un descenso fluvial por el río ya citado, afluente del Amazonas, junto a un grupo de soldados españoles, de servidores indígenas y de negros que viajaron en calidad de esclavos. Sin embargo, Pedro de Ursúa no concluyó la expedición, pues fue asesinado tras un levantamiento ideado por Lope de Aguirre, un soldado que tomó su relevo como jefe de la empresa. Este la convirtió en un proyecto personal debido a su ansia de liderazgo, aunque en teoría el que ostentó el poder en un primer momento fue Fernando de Guzmán, quien ejecutó el plan ideado por el anterior. Este último terminó también asesinado por Aguirre, junto a cada uno de sus simpatizantes.

A partir de este momento, la misión adquirió una nueva finalidad, de modo que el objetivo de conquistar y poblar las tierras míticas de El Dorado como parte del dominio español y de enriquecerse con sus recursos auríferos fue reemplazado por una rebelión contra la Corona, pues, según nos explica Margalef, "Lope de Aguirre pretende crear un reino independiente de España, en el que él sería el Príncipe» (2012: 23), de modo que negó la autoridad del Rey de España en ese momento, Felipe II. Tras concluir la misión, fue ajusticiado por los crímenes que había cometido y por desobedecer la autoridad real.

Otros expedicionarios posteriores fueron Hernán Pérez de Quesada, Antonio de Berrío, sir Walter Raleigh, etc. Algunos de estos alcanzaron sus objetivos geográficos, pero no hallaron la fortuna que esperaban encontrar. Así, creyendo que habían errado, reubicaron en numerosas ocasiones el lugar del botín, de modo que se dio inicio a la persecución de un fantasma por la zona septentrional de Sudamérica. Cuando algunos expedicionarios creyeron haber llegado al lugar indicado, esto es, a la laguna de Guatavita, iniciaron un plan para tratar de drenar su agua con el objetivo de extraer las numerosas piezas de oro que

5 Sobre ella, el cronista Juan Rodríguez Freyle escribió lo siguiente en 1636: «A este tiempo desnudaban al heredero en carnes vivas, i lo untaban con una tierra pegajosa i lo espolvoreaban con oro en polvo i molido, de tal manera que iba cubierto todo de este metal. Metíanle en la balsa, en la cual iba parado, i a los piés le ponian un gran monton de oro i esmeraldas para que ofreciese a su dios» (Rodríguez, 1859: 14). 
esperaban hallar. Por esta razón, sabemos que la fiebre del oro se extendió a lo largo de los siglos, y en ningún momento desapareció la creencia en unas tierras auríferas.

En cuanto a la plasmación de esta historia en nuestra película objeto de estudio, cabe señalar que la recreación cinematográfica realizada por Carlos Saura comienza con una escena en la que aparecen unos hombres celebrando un ritual, según el cual el cacique de la tribu, cubierto de oro, se adentra en la laguna con cuatro acompañantes que sostienen los remos. Por tanto, hasta el momento el espectador presencia un retrato fiel de la leyenda a la que hemos aludido anteriormente, como podemos observar en la siguiente imagen tomada del filme:

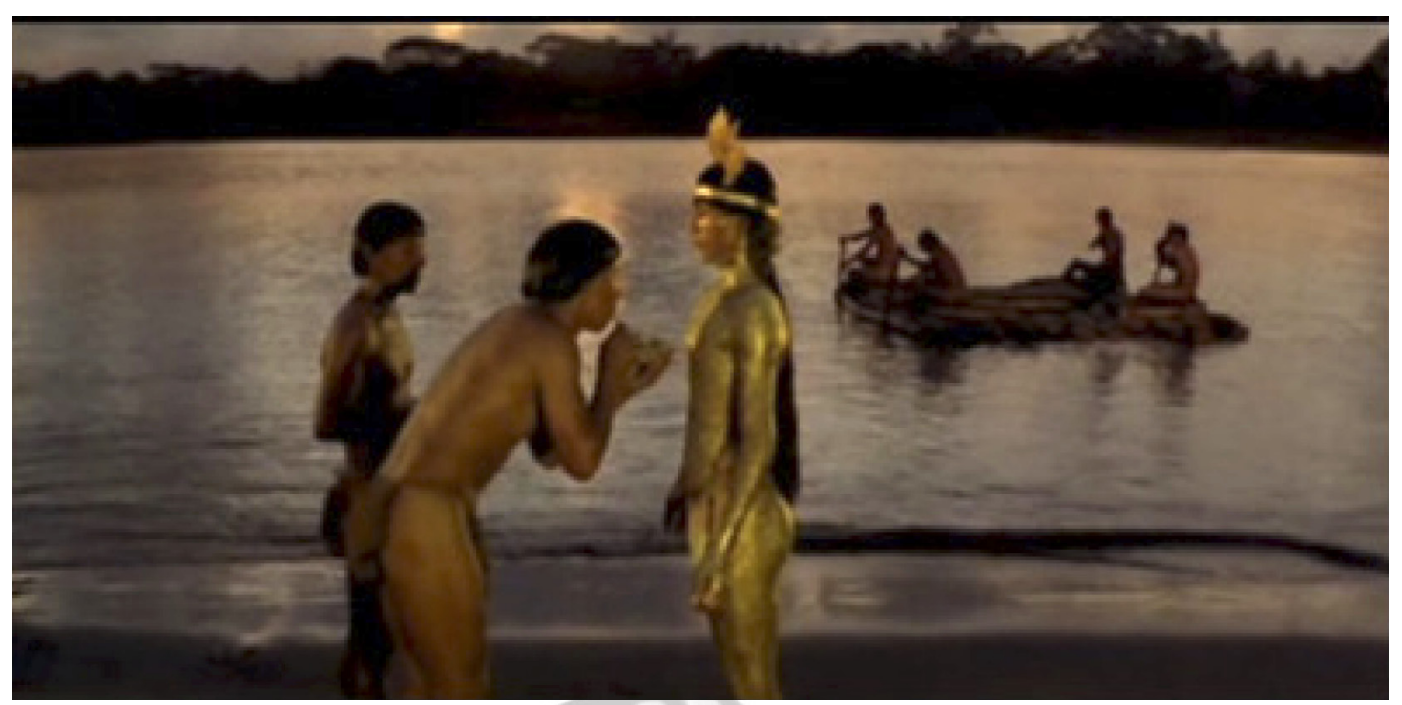

Ritual muisca en la laguna de Guatavita.

Tras esta ceremonia, el enfoque recae en los expedicionarios, que se preparan para partir de Perú en busca de esta tierra tras el alentador discurso del gobernador Pedro de Ursúa sobre las riquezas que conquistarían. Sin embargo, la aventura no empieza con buen pie, pues las embarcaciones en las que viajarán se rompen debido al mal estado de la madera, como presagio fatal de lo que estaba por venir. Pese a esto, el gobernador decide continuar con la empresa utilizando las que quedan disponibles y su bergantín, pero deja en tierra algunos recursos y a muchos de los animales destinados a poblar ese territorio, que tanto dinero habían costado.

A este mal augurio se suma, posteriormente, el asesinato a manos de unos indios de los hombres que envía en un primer momento para reunir víveres para el resto de la tripulación que le acompaña en la empresa, al mando del capitán García de Arce. De este modo, los planes iniciales del gobernador se van viendo truncados a medida que avanzan en su descenso por el río. Asimismo, la falta de víveres hace mella pronto en sus acompañantes, al tiempo que el ánimo de las personas que han marchado en la expedición se va viendo truncado. Con el paso de las semanas, la aventura resulta monótona y agotadora, pues el descenso por el río es lento y la vegetación que les rodea y las aguas amazónicas son siempre las mismas, como se observa en la siguiente imagen extraída del filme, a lo que se suman ciertas desavenencias que van surgiendo con tribus indias con las que se topan: 


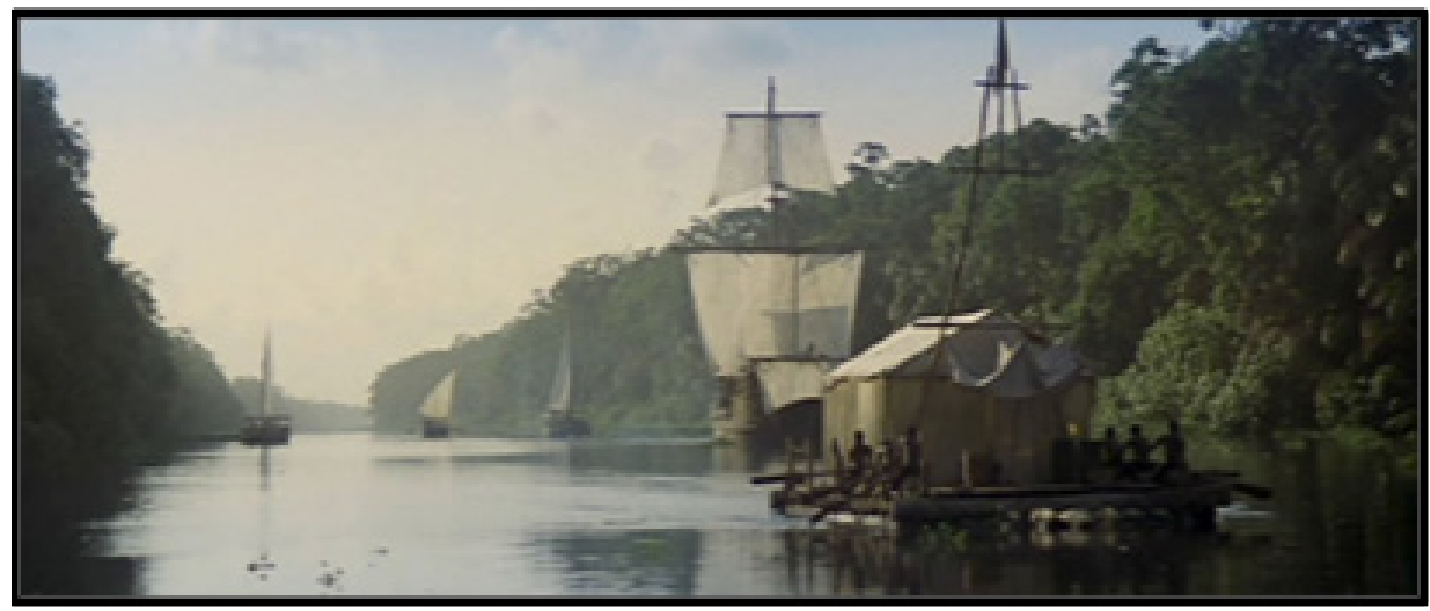

Descenso de las embarcaciones por el río, rodeado de una vegetación impenetrable.

Debido al poco éxito de la exploración, algunos soldados tratan de hacer reflexionar al gobernador con el objetivo de volver sobre sus pasos hasta Perú y abandonar su cometido, pero este no cede y decide continuar con la empresa. Asimismo, se manifiesta de manera progresiva una desorganización en las tropas españolas y se sucede el descontento respecto a la autoridad de Pedro de Ursúa, ya que los soldados consideran que su relación con doña Inés de Atienza le hace cambiar de carácter y de parecer. De este modo, posteriormente se da el motín ideado por Lope de Aguirre, que se convierte en instigador del asesinato de Pedro de Ursúa.

Tras la muerte de este, Fernando de Guzmán se alza con el liderazgo de la expedición, aconsejado por Lope de Aguirre, quien comienza a asesinar a todos los que suponen un impedimento para conseguir su fin. Tras esto, las matanzas se suceden, no solo entre los propios españoles acusados de traición, sino también entre el resto de la cuadrilla, es decir, los indígenas y los negros con los que viajan los españoles cuando los primeros se niegan a trabajar en condición de esclavos. Después de un tiempo, siguiendo la idea de Lope de Aguirre de rebelarse contra la Corona, nombran a Guzmán príncipe de Perú y de Chile, y desde ese momento le obedecen con total fidelidad.

La empresa continúa, pero las provisiones escasean cada vez más, a la vez que el número de embarcaciones se ve reducido por su mal estado. La desesperación por no encontrar el lugar deseado aumenta a medida que pasa el tiempo y continúan sin lograr su objetivo. Al mismo tiempo, la locura de Lope de Aguirre va aumentando y, al desconfiar de Guzmán y de sus hombres, acaba matándolos al considerarlos traidores, así como también a doña Inés, quien había tratado de poner a la hija de Lope en su contra, Elvira, su bien más preciado. Este último asesinato causa la enemistad entre padre e hija, quien considera que su padre se ha vuelto un cruel sanguinario que ha perdido la cordura a lo largo de los meses que navegan por el río. Tras estas muertes, asume él mismo el mando y se autoproclama «príncipe de la libertad». Su locura llega al extremo cuando tiene un sueño premonitorio en el que mata a su propia hija, lo cual ocurre finalmente, según cuenta una voz en off. Del mismo modo, este será también ajusticiado por los reprochables actos que lleva a cabo, sin haber encontrado El Dorado.

Se trata, en definitiva, de una película que podría considerarse fiel a la historia y a la leyenda que circulaba en la época si la comparamos con otras como la realizada por el director alemán Werner Herzog, titulada Aguirre, la cólera de Dios (1972), la cual contiene 
mayores inexactitudes. A este respecto, siguiendo a Margalef, cabe señalar que «la idea de Carlos Saura era hacer una película siguiendo los acontecimientos que se relatan en las crónicas que sobre Lope de Aguirre escribieron en la época quienes participaron en aquella expedición en busca de El Dorado» (2012: 21). De este modo, vemos respetados la época de la expedición, los lugares transitados, los protagonistas y gran parte de sus actuaciones, aunque nuestro director confiere en el filme una mayor libertad a sus personajes. Esto último hace que no hablemos en términos de adaptación fiel, sino de recreación, pues sigue unas líneas principales básicas establecidas por las crónicas. Así, siguiendo las palabras de Margalef, concluimos señalando que la película «encierra un trasfondo histórico y conjuga la vieja ambición humana del enriquecimiento fabuloso y súbito con la locura de un hombre que se subleva contra la legalidad establecida» (2012: 20).

\section{ASPECTOS CINEMATOGRÁFICOS PUESTOS EN JUEGO POR SAURA}

De lo anteriormente explicado podemos deducir que se trata de un filme centrado en los españoles y en su autodestrucción pues, aunque aparezcan también indios y negros, el peso de la acción recae en los capitanes y soldados, cuya acción se aleja del heroísmo épico que podríamos esperar de una historia de este calibre. De este modo, el filme aporta un relato desmitificador a la par que verista de una de tantas expediciones españolas destinadas a explorar y conquistar un territorio americano en poder de los indígenas.

Frente a una visión exaltadora o nacionalista, Carlos Saura decide centrarse en los aspectos más desagradables de la conducta humana, como son las traiciones y los asesinatos perpetrados en nombre del ansia de poder, que lleva en ocasiones a la locura. Así, el director muestra a qué extremos pudieron llegar aquellas personas que protagonizaron este tipo de aventuras a lo largo de la historia, ahondando en la psicología de algunos de sus protagonistas, como es el caso de Pedro de Ursúa, cuya perdición se debe a ese amor irrefrenable que siente por doña Inés de Atienza, o de Lope de Aguirre, cuya capacidad de raciocinio se ve finalmente dominada por el bien material y el ansia de poder, tras un periplo que le resulta agotador física y mentalmente.

Asimismo, a lo largo de la película observamos reflejada la violencia del conquistador, de modo que los expedicionarios pueden ser considerados antihéroes debido a su codicia. A esto último hemos de sumar, como hemos apuntado anteriormente, el ambiente en el que se encuentran, es decir, la selva tropical, el calor, los ríos interminables, el hambre y el hastío; causas que fueron logrando que surgiesen dudas, envidias y traiciones entre la propia tropa española. Por todo lo dicho, podríamos afirmar que la película está caracterizada por tintes de tragedia en cuanto a la lucha del hombre por el poder y a las acciones perversas que es capaz de llevar a cabo para conseguir sus objetivos.

La fuerza dramática de la historia reflejada en la película reside, precisamente, en las riñas permanentes y en la creciente tensión entre los expedicionarios a medida que se va apoderando de ellos la locura y el ansia de poder y de riquezas. Sin embargo, el ritmo de avance de la acción central es lineal y lento, pues una buena parte de la película está centrada en escenas que transcurren en su descenso por el río, las cuales resultan en ocasiones demasiado densas y reiterativas.

Esta deficiencia se suple, según consideramos, con la muy lograda ambientación y la atmósfera convincente en que se desarrollan los acontecimientos, a lo cual también contribuyen los trajes propios del siglo XVI utilizados por los actores y su excelente banda 
sonora. Todos estos aspectos ayudan a que el espectador se sienta presente en ese mismo territorio y en la época en que acontece las acciones que va visualizando. La fotografía recae en manos de Teo Escamilla, quien ofrece en numerosas ocasiones un acertado travelling con el que logra transportar al espectador a ese ambiente opresivo gracias a su captación de la inmensidad de la selva amazónica y del inacabable río, que sirven como telón de fondo para la historia. A estos planos abiertos del paisaje se suman los primeros planos, los cuales resultan emotivos cuando se ahonda en la actuación y en la psicología de los personajes.

Asimismo, sobresale la apropiada actuación de los personajes, especialmente la de Omero Antonutti (Lope de Aguirre) y la de Lambert Wilson (Pedro de Ursúa), los protagonistas, a lo que hemos de sumar la de Gabriela Roel (Inés de Atienza) y la de una joven Inés Sastre (Elvira), la cual debuta en esta película. Otro de los grandes papeles de la película lo protagoniza Eusebio Poncela (Fernando de Guzmán), cuya caracterización ejemplifica las libertades que se toma Saura al presentarnos la historia, pues, en este caso, el director convierte al personaje en un homosexual, lo cual no aparece evidenciado en las crónicas ni en ningún otro relato que recoge este mismo asunto.

Finalmente, hemos de dedicar unas líneas a la excelente banda sonora del filme, pues, en ocasiones, son los propios indígenas los que tocan instrumentos de percusión y de viento con melodías propias de su pueblo, las cuales sirven para recrear el ambiente de la historia. A la vez, algunos soldados españoles tocan la guitarra para acompañar ciertas canciones tradicionales, como la titulada «Las morillas de Jaén», con las cuales se recrea el ambiente renacentista de la época. Por esto, podemos afirmar que el trabajo llevado a cabo por Alejandro Massó, quien se encargó de componerla tras haberse documentado sobre aquella época, con la ayuda de Joaquín Díaz, resulta, a nuestro juicio, impecable.

Con todo este aparato desplegado bajo las órdenes del director, Carlos Saura, obtenemos finalmente un producto cinematográfico que refleja de manera notable la realidad de una expedición en la que sus protagonistas lo pierden todo, incluso la cordura y, en muchas ocasiones, la vida, por lo que se refleja claramente la miseria humana de una manera dura $y$, a su vez, veraz. Esto último se observa, entre otras, en la escena en que la atención recae sobre los cuerpos sin vida de todo un poblado indígena, apilados en una misma cabaña, el cual ha sido masacrado a manos de los españoles, y es precisamente por esta imagen negativa que se da de las aventuras en el Nuevo Mundo lo que pudo causar la mala acogida del filme, como a continuación comentaremos.

\section{ACOGIDA POR PARTE DE LA CRÍTICA Y VALORACIÓN DEL PÚBLICO ${ }^{\circ}$}

Se ha repetido en numerosas ocasiones que nos encontramos ante la producción cinematográfica más cara hasta el momento de la historia del cine español, pues el gobierno, el cual la financió, destinó un gran presupuesto para su producción y rodaje. Concretamente, el filme contó con el patronazgo de la Sociedad Quinto Centenario, el cual destinó 1000 millones de pesetas, cifra que equivale a 6 millones de euros, pues se depositó en Carlos Saura una gran confianza a la hora de la repercusión positiva que se esperaba que tuviese su obra. Sin embargo, estuvo muy lejos de lograr el alcance y la acogida que se esperaba; de hecho, el largometraje fue nominado a nueve Premios Goya en 1988 y a la Palma de Oro del Festival de Cannes como Mejor Película, pero no obtuvo ningún galardón.

6 Los datos de este apartado han sido extraídos de Margalef, 2012: 20-24.

Quaderns, 14 (2019), pp. 43-52 
La gran cantidad de dinero que se invirtió en su filmación ha sido una de las críticas que ha recibido la película desde entonces, pues se destinaron sumas considerables a la cantidad de actores que aparecen, de diferente procedencia, al despliegue que implicaba la aparición de una flota con numerosas embarcaciones, a los escenarios de Costa Rica con paisajes preparados y a los numerosos animales que intervienen en ella, entre otros.

Entre las causas de su fracaso, la crítica ha alegado que pueden citarse el largo metraje de la película -149 minutos-, su ritmo lento, su falta de tensión dramática, la mala gestión publicitaria del momento, el desinterés general del público por esa parte de la historia y el desarrollo de la acción, cuyo brillante planteamiento inicial va decayendo progresivamente y el público desconecta de la historia por la ausencia de actividad de los personajes. De este modo, posiblemente podamos encontrar la explicación también en el hecho de que el público esperaba un producto cinematográfico más dinámico, en sintonía con el cine norteamericano del momento $y$, frente a este, se encontró con una película que se ha calificado de lenta en su avance y de carente de emoción.

\section{CONCLUSIONES}

Estamos ante uno de los muchos episodios surgidos a partir del choque de esas dos culturas que señalábamos al comienzo, pues los españoles encontraron en esas tierras el lugar idóneo en el que proyectar sus anhelos de riqueza y de poder, frente a los nativos, que sufrieron las consecuencias de la invasión y la conquista. A pesar de ser de sobra conocidas estas historias, el cine español no ha abordado el tema del Descubrimiento y la Conquista de la manera en que podría haber sido explotado, probablemente debido a la leyenda negra que circula sobre estos acontecimientos y la negativa visión del papel de España en ellos. Sea como fuere, estamos ante uno de los primeros productos cinematográficos que abordan la aventura de Pedro de Ursúa y Lope de Aguirre, lo cual aumenta el valor de nuestro objeto de estudio como obra cultural vinculada con la historia de nuestro país, con la que podemos estar más o menos de acuerdo, pero que, en cualquier caso, se ha de conocer y estudiar.

Se trata, en definitiva, de una historia vasto conocida, lo cual se evidencia a partir de su recreación cinematográfica y de las múltiples obras literarias que han acogido como tema esta historia. Entre los primeros productos culturales, podemos mencionar el ya citado trabajo del director Werner Herzog en Aguirre, la cólera de Dios (1972), el de Terry Cunningham en la miniserie El Dorado: El Templo del Sol (2000), e incluso el de La ruta hacia El Dorado (2000), de DreamWorks. Finalmente, entre las obras literarias que abordan este asunto, encontramos El camino de El Dorado (1947), de Arturo Uslar Pietri, La aventura equinoccial de Lope de Aguirre (1947), de Ramón José Sender Garcés y Lope de Aguirre, príncipe de la libertad (1979), de Miguel Otero Silva.

Por todo lo explicado, podemos concluir nuestra investigación afirmando que se trata de un mito que atrajo no solo a los conquistadores del momento, sino a miles de personas que, a lo largo de los siglos, se han querido hacer eco, de uno u otro modo, de las aventuras protagonizadas por estos hombres. Este episodio permite vincular, en cierta medida, la historia y la ficción, pues evidencia, una vez más, la capacidad imaginativa o fabuladora del ser humano, que se mantiene intacta pese al paso del tiempo. 


\section{BIBLIOGRAFÍA CITADA}

BARRIENTOS, Juan José (1994): «Regreso a Omagua: Carlos Saura y Lope de Aguirre», Actas Irvine-92: [Actas de XI Congreso de la Asociación Internacional de Hispanistas], 4 (1994), pp. 309-314; <https://cvc.cervantes.es/literatura/aih/pdf/11/aih_11_4_037.pdf> [consulta: 5 junio 2019].

Cervera, César (2015): "El mito de "El Dorado", la locura y la perdición de los conquistadores españoles», $A B C$ España, 17 de febrero de 2015, s. p.; <https://www.abc.es/ espana/20150217/abci-dorado-mito-conquistadores-espanoles-201502162212.html> [consulta: 5 junio 2019].

ColÓN, Cristóbal (2006): Diario de a bordo, ed. Luis Arranz Márquez, Madrid, Edaf.

CORTÉS de MonRoy y PizARRO AltamiRANo, Hernán (1866): Cartas y relaciones de Hernán Cortés al emperador Carlos V colegidas e ilustradas por don Pascual de Gayangos, de la Real Academia de la Historia de Madrid; correspondiente del Instituto de Francia, ed. Pascual de Gayangos y Arce, París, Imprenta Central de los Ferro-Carriles.

Fernández de OVIedo, Gonzalo (2019): Sumario de la Historia Natural de las Indias, s. e., Barcelona, Red, 2019.

Gómez TABANERA, José Manuel (1988): «Presentación», en Demetrio Ramos (ed.), El mito de

El Dorado, Madrid, Istmo, pp. V-XXIII.

LuCEnA SALmoral, Manuel (1985): El mito de El Dorado, Madrid, Grupo 16.

MARGALEF, Albert (2012): «El Dorado, recreación cinematográfica de un mito», Filmhistoria Online, 22.1, pp. 1-30; <http://revistes.ub.edu/index.php/filmhistoria/article/ view/13872/17184> [consulta: 5 junio 2019].

MORA, Judith (2014): «El Dorado: tras la leyenda que forjó América», Clío, 147, pp. 40-47; $<$ https://dialnet.unirioja.es/servlet/articulo?codigo=4629230 $>$ [consulta: 5 junio 2019].

OSORIO, Betty (2007): «El chamán y el agua: símbolos de resistencia cultural», Cuadernos de Literatura, 11.22, pp. 46-57; <https://dialnet.unirioja.es/descarga/articulo/5228489.pdf> [consulta: 5 junio 2019].

RodríGUEZ FREYLE, Juan (1859): Conquista i descubrimiento del Nuevo Reino de Granada de las Indias Occidentales del Mar Oceano, i fundacion de la ciudad de Santa Fe de Bogota, primera parte de este reino donde se fundó la real audiencia i chancilleria, siendo la cabeza..., ed. Felipe Pérez, Bogotá, Imprenta de Pizano y Pérez. 